Article

\title{
Precise Analysis on Mutual Inductance Variation in Dynamic Wireless Charging of Electric Vehicle
}

\author{
Ainur Rakhymbay ${ }^{1}$, Anvar Khamitov ${ }^{1}$, Mehdi Bagheri ${ }^{1, *}$ (D), Batyrbek Alimkhanuly ${ }^{1}$, \\ Maxim Lu ${ }^{1}$ and Toan Phung ${ }^{2}$ \\ 1 Department of Electrical and Electronic Engineering, School of Engineering, Nazarbayev University, \\ Astana 010000, Kazakhstan; arakhymbay@nu.edu.kz (A.R.); anvar.khamitov@nu.edu.kz (A.K.); \\ batyrbek.alimkhanuly@nu.edu.kz (B.A.); maxim.lu@nu.edu.kz (M.L.) \\ 2 School of Electrical Engineering and Telecommunications, University of New South Wales, Sydney, \\ NSW 2052, Australia; toan.phung@unsw.edu.au \\ * Correspondence: mehdi.bagheri@nu.edu.kz; Tel.: +7-71-7270-9251
}

Received: 10 February 2018; Accepted: 5 March 2018; Published: 11 March 2018

\begin{abstract}
Wireless power transfer provides an opportunity to charge electric vehicles (EVs) without electrical cables. Two categories of this technique are distinguished: Stationary Wireless Charging (SWC) and Dynamic Wireless Charging (DWC) systems. Implementation of DWC is more desirable than SWC as it can potentially eliminate challenges associated with heavy weight batteries and time-consuming charging processes. However, power transfer efficiency and range, lateral misalignment of coils as well as implementation cost are issues affecting DWC. These issues need to be addressed through developing coil architectures and topologies as well as operating novel semiconductor switches at higher frequencies. This study presents a small-scale dynamic wireless power transfer system for EV. It specifically concentrates on analyzing the dynamic mutual inductance between the coils due to the misalignment as it has significant influence on the EV charging process, particularly, over the output power and overall efficiency. A simulation study is carried out to explore dynamic mutual inductance profile between the transmitter and receiver coils. Mutual inductance simulation results are then verified through practical measurements on fabricated coils. Integrating the practical results into the model, an EV DWC power transfer simulation is conducted and the relation between dynamic mutual inductance and output power are discussed technically.
\end{abstract}

Keywords: coil design; Dynamic Wireless Power Transfer (DWPT); electric vehicle (EV); mutual inductance

\section{Introduction}

EVs have gradually become a reasonable replacement for conventional fossil fuel cars with internal combustion engines. Their use will assist air pollution and $\mathrm{CO}_{2}$ emission reduction, and also extensive deployment of green energy sources [1-4]. Moreover, general public interest has motivated car manufacturers towards the development of various electric vehicles [2,5], such as battery electric vehicles (BEV), hybrid electric vehicles (HEV), fuel cell electric vehicles (FCEV), and fuel cell hybrid vehicles (FCHV) [6]. The development and improvement of battery storage systems as well as implementation of various techniques for the monitoring and control of battery states facilitates the attractiveness of EVs $[7,8]$. EV charging can be accomplished either using cables (wired) or wirelessly. The wireless charging technique compared to the traditional wired approach has recently become more engaging in terms of safety, suitability and simplicity $[9,10]$. Since charging cables are not required for Wireless Power Transfer (WPT); the hazards of tripping, arcing or getting electrocuted while plugging or unplugging batteries in a wet environment are eliminated. The safety and efficiency of WPT systems can be attained by the installation of new protective devices, interconnection protection systems and 
earthing arrangements $[11,12]$ that monitor various faults and respond to them as quickly as possible. The applications of this technology can be found in wireless chargers for both small-scale appliances such as toothbrushes, cellular phones [13-15] and medical implants [16,17] or even for high-power charging of EV batteries [18,19].

Based on the operation principle, WPT systems for EV charging can be separated into two categories, i.e., static and dynamic. Static Wireless Charging (SWC) systems transmit power over the air gap between two stationary positioned coils, while a Dynamic Wireless Charging (DWC) system potentially allows one to transfer power from a stationary transmitter to the receiver coil of a moving object, e.g., an EV [20-23]. In a study by Choi et al. [2], one of the major challenges associated with commercialization of EVs is the battery durability. Despite of all the advances in the field of material technology, EV batteries are still expensive and characterized by slow charging times, low energy density and limited lifetime [24-26]. FCEVs, where a fuel cell directly converts chemical energy into electrical energy, have high efficiency and produce zero emissions, but the cost and hydrogen storage are considered limiting factors of such vehicles [27]. In case of the stationary wireless charging, the EV can only be charged once it is at a specific charging station. For transit, the vehicle must solely rely on its internal energy source and, therefore, it must carry a relatively large and heavy battery in order to cover a reasonable distance between the charges. Consequently, problems associated with the EV energy storage such as low power density, long recharging time and heavy weight are created inherently. On the other hand, by employing the DWC technique, the EV could be charged while it is in motion and consequently, the size of the carried battery can potentially be reduced [1-3]. Therefore, implementation of DWC systems is considered as a viable solution to increase the competitiveness of EVs in the marketplace as well as technically overcome the charging issues.

Dynamic wireless power transfer systems have a number of advantages that could lead to the extensive deployment of EVs [2,3]. Firstly, the allowable traveling range of the vehicle could be improved due to the possibility of continuous charging of its battery while moving forward [28-30]. Secondly, charging during motion will eliminate the need for large energy storage. This, in turn, will reduce the vehicle's weight and increase the travel distance. Lastly, Dynamic Wireless Power Transfer (DWPT) systems which employ the principles of the DWC technique allow charging several vehicles simultaneously and reducing the charging time. However, practical application of DWPT systems for EV charging is associated with a set of challenges. The most important issues which need to be addressed are the low power transfer efficiency and considerable power losses occurring during the process [3]. The cause of these problems is the dynamic nature of charging. To be precise, there is a constant lateral misalignment between the transmitter and the moving receiver coils [4]. This in turn results in considerable power transfer efficiency degradation, which is not desirable.

The concept of WPT was firstly introduced by Nicola Tesla in the early 1890s when he conducted an experiment on wireless energy transfer through the air between static objects [31-33]. Later, the first implementation of a DWPT system in EV charging was performed at the Lawrence Berkeley National Laboratory in 1976 [2,34,35]. Recently, a research team from University of Auckland has accomplished a noticeable achievement in the development of electric buses that are powered wirelessly during motion [22,36]. They have designed a prototype of a $400 \mathrm{~m}$ long track that wirelessly transmits $100 \mathrm{~kW}$ to a train [37]. Furthermore, the researchers from Korea Advanced Institute of Science and Technology (KAIST) have developed several generations of Online Electric Vehicles (OLEVs). They have implemented an OLEV project, which was capable of transmitting $100 \mathrm{~kW}$ of power with $85 \%$ efficiency [2,3]. Moreover, the research team of Oak Ridge National Laboratory (ORNL) [38] has proven that the power transfer efficiency of DWPT system depends mainly on the position of the transmitter coil with respect to the pick-up coil. Therefore, the ultimate goal of this research is to analyze the effect of transmitting and receiving coil positions on DWC system efficiency and examine variable coupling factors between the coils.

There are three common techniques applied in DWPT systems for EV charging, namely: Inductive Power Transfer (IPT), Capacitive Power Transfer (CPT) and coupled magnetic resonance [1]. 
The efficiency of both IPT and CPT methods is high, but the range of power transfer is low. The IPT method is preferable for EV charging because of the high power transfer rate which can be transferred comparing to the CPT method. Coupled magnetic resonance is considered as a special case of the IPT method, but with a medium range of power transfer. DWPT systems based on the coupled magnetic resonance have a high quality factor $Q$ and operate at the high frequency range, up to $10 \mathrm{MHz}$ [1]. The DWPT system proposed in this work applies the coupled magnetic resonance method to transfer $100 \mathrm{~W}$ to a $13 \Omega$ resistive load at $85 \mathrm{kHz}$.

According to the power tracks' construction, the DWPT systems can be divided into lumped or concentrated and stretched or distributed. In distributed DWPT systems, the transmitter coil length is greater than that of the moving receiver coil. On the contrary, concentrated DWPT systems have transmitter and receiver coils of identical size and shape [4]. The advantages of the stretched transmitter coils include design simplicity and less number of components compared to the lumped tracks [39]. However, the limitation of such distributed systems is their low power transfer efficiency. This fact was proven by the research team from KAIST [28]. In this experiment, $27 \mathrm{~kW}$ of power was transferred to a vehicle wirelessly with $74 \%$ efficiency, while the typical expected efficiency is greater than $90 \%$. On the other hand, a concentrated transmitter system consists of a number of coils that has the same size as the receiver coil, which yields higher transfer efficiency [29]. Thus, the proposed system implements the lumped design of the power track. In Figure 1, the transmitter and receiver coils are presented as blocks, which include compensation circuit and a coil. In addition, in order to improve the efficiency of the transfer further, each transmitter coil requires a set of compensation elements to be connected to it. However, this in turn results in greater number of elements and therefore more complex designs. Thus, the total cost of the lumped DWPT systems is higher than that of distributed tracks due to the increased number of circuit elements. In order to overcome this challenge, most of the applications utilize a set of transmitter coils connected in series or in parallel, which are supplied by a single power source instead of separate ones. Furthermore, the transmitter coils should be mounted sufficiently far away from each other in order to reduce losses on self-coupling between them. Such design allows transmitting power when the receiver coil is coupled with the transmitter and stopping the transfer when the receiver is located between the two transmitters. This approach eliminates power pulsations and results in higher power output. Thus, the distance between adjacent transmitters must be selected precisely and accurately [40]. Approaches to transfer power in an efficient manner in magnetic resonant coupling for different configurations of transmitter and receiver coils are shown in the study of [41,42]. In addition, the power transfer efficiency of the DWPT systems depends on the dimensions and shape of the coils, type of the material used and the design of coil shielding [43-45]. The given study compares circular- and square-shaped coils in terms of power transfer efficiency. In addition, a 3D simulation study is performed in order to identify the optimal spacing between the transmitter coils.

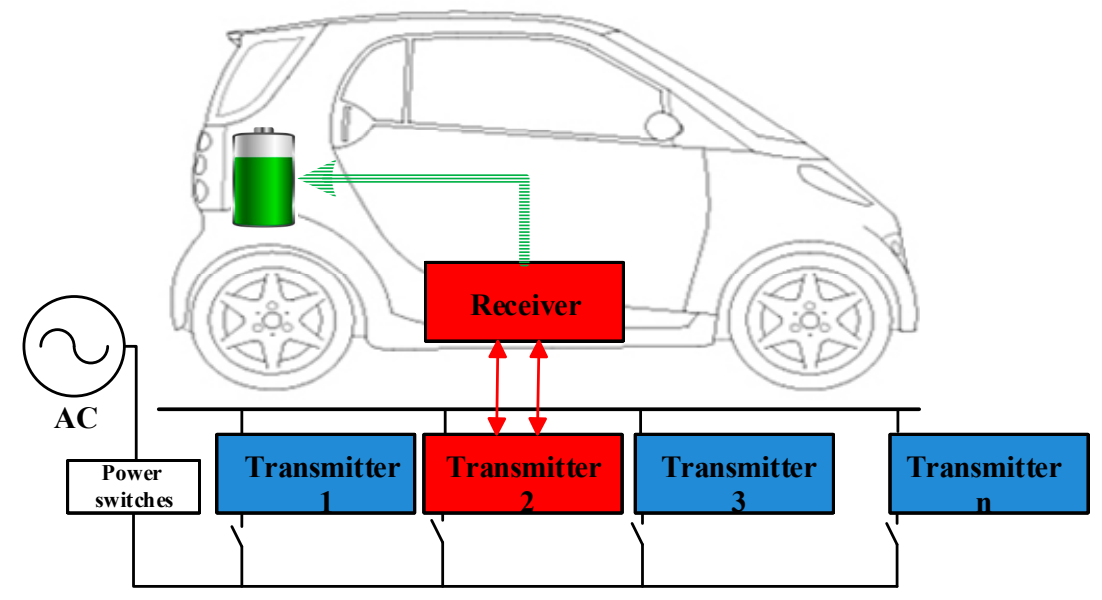

Figure 1. DWPT system with parallel transmitters. 
Another important design consideration in DWPT systems is the choice of primary and secondary side compensation circuits. For instance, in order to enhance the efficiency of the power transfer, the compensation capacitors are connected in series or in parallel with the primary and secondary side inductors. Proper selection of the compensation topology will also allow soft switching of power electronic instruments, minimize the inductance leakage, tune the system to the required resonance frequency, and reduce the VA rating of transferred power. There are four fundamental compensation circuits, which are denoted as: Series-Series (SS), Series-Parallel (SP), Parallel-Series (PS) and Parallel-Parallel (PP). Each topology has benefits and drawbacks, and different transfer efficiency rates. It has been clearly demonstrated in previous work [46], that SS and PS topologies are found to be the most efficient, resulting in $70.3 \%$ and $70.4 \%$ of efficiency, respectively. As the output efficiencies are relatively low, more advantageous compensation circuit topologies such as Inductor-Capacitor-Capacitor (LCC) and Inductor-Capacitor-Inductor (LCL) are introduced [47-51]. The utilization of these novel compensation circuits can enable Zero Voltage Switching (ZVS) and Zero Current Switching (ZCS) modes of operation, hereby increasing the power transfer efficiency. However, Kan et al. [45] claimed that the use of LCC circuits is the most efficient in terms of power transfer. Therefore, the design of this proposed study employs LCC compensation of the primary side coil. However, since the compensation circuit has a number of elements, it would also be beneficial to decrease the overall complexity of the system. Therefore, the secondary side coil is tuned in series with a compensation capacitor.

Having considered the abovementioned points, this study investigates the power transfer efficiency of a DWPT system transmitting $100 \mathrm{~W}$ at $85 \mathrm{kHz}$. Moreover, a comprehensive analysis of square- and circular-shaped coils was performed. In order to identify the electromagnetic parameters of the coils, a simulation study was employed and a validation was practically performed by the proposed effective measurement method of the mutual inductance. The study is structured as follows: Section 2 presents the proposed system description, Section 3 provides the simulation results of the various coil designs, Section 4 compares simulation and experiment results of the variable mutual inductance between two and three coils, while Section 5 discusses the simulation results of the proposed DWPT system, and Section 6 summarizes the outcomes of the study, presents the conclusions and future works.

\section{DWPT System Model}

This research study analyzes the performance of a DWPT system equipped with two stationary transmitters and one moving receiver. Generally, the practical layout of such system consists of more than a pair of transmitter coils. However, for the simulation and analysis simplification, a system with just two power pads was studied. Nevertheless, the basic principle of operation is the same.

The schematic diagram of the proposed system with the specified notation of parameters is presented in Figure 2. As mentioned, this system consists of two transmitter tracks, which are supplied by a common DC source $V_{D C}$. The full-bridge inverter with four switches $S_{1}, S_{2}, S_{3}$ and $S_{4}$ was used to convert input DC voltage into AC voltage since the nature of magnetic resonance coupling method is based on AC current. Moreover, in order to achieve proper resonance state and increase the system efficiency, each transmitting coil is connected to the LCC compensation circuit. The compensation elements such as inductor and two capacitors are denoted as $L_{t 1}, C_{1}, C_{1 t}$ for the upper transmitter and $L_{t 2}, C_{2}, C_{2 t}$ for the lower transmitter, respectively. The corresponding stray resistances are represented as $R_{t 1}, R_{1}, R_{t 2}$, and $R_{2}$. In addition, capacitors $C_{t 1}$ and $C_{t 2}$ are included into the circuit in order to adjust inverter's reactance. The two transmitter coils' self-inductances $L_{1 t}$ and $L_{2 t}$ successively couple with the receiver coil's self-inductance $L_{1 r}$ as it moves over them and create mutual inductances $M_{1}$ and $M_{2}$, respectively. The overall stray resistances of the first and the second transmitters are designated as $R_{1 t}$ and $R_{2 t}$. Moreover, switches $S_{11}$ and $S_{22}$ are used to switch on and off the transmitter 1 or transmitter 2 when it is required. Currents $I_{t 1}$ and $I_{t 2}$ flow through the compensation circuits, while $I_{1}$ and $I_{2}$ are the transmitting currents and $I_{L}$ is the induced current, which flows through 
the secondary-side compensation capacitor $C_{1 r}$ connected in series with its stray resistance $R_{1 r}$ and equivalent load resistance $R_{\text {Load }}$ of system.

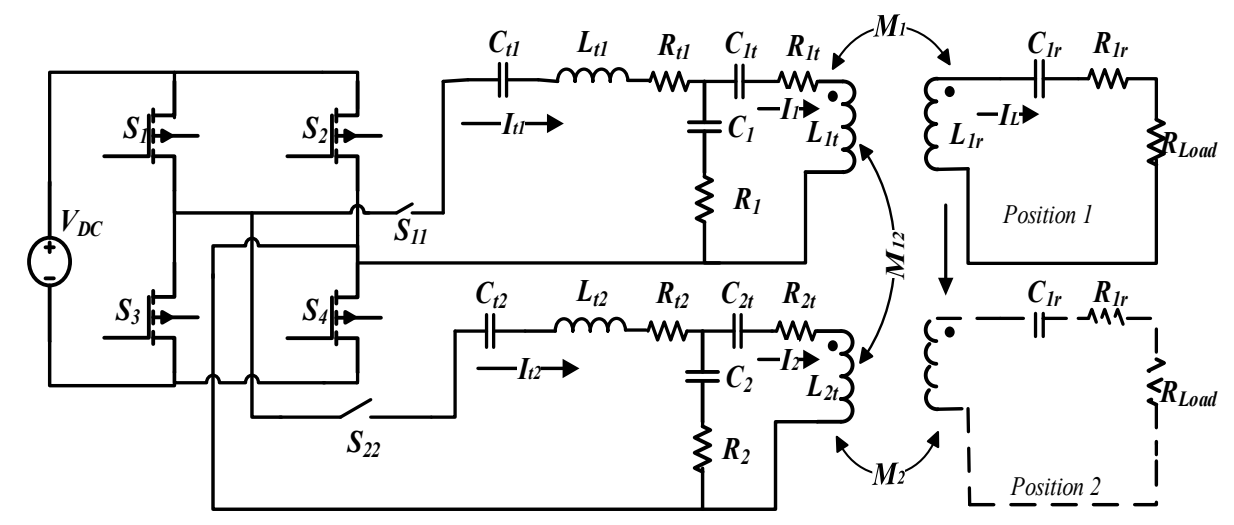

Figure 2. The schematic circuit of the proposed DWPT system.

As described in Section 1, a dynamic WPT system is an extended version of stationary WPT system and the fundamentals of their operation are common. Specifically, since in case of stationary WPT system EV is motionless with respect to the transmitter coil, the mutual inductance between transmitter and receiver coils is constant over the whole charging cycle. However, in case of a dynamic WPT system the mutual inductance varies in accordance with the vehicle's movement. This can be interpreted as creating a number of stationary circuits. Hence, a simplified circuit of WPT system depicted in Figure 3 is used to explain the basic operation. In Figure 3, AC voltage $V_{1}$ is applied to the primary-side coil with inductance $L_{1}$. It transfers power to the transmitter coil and then voltage $V_{2}$ is induced in the secondary-side coil with inductance $L_{2}$. As a result, the mutual inductance $M$ is created between them. The primary and secondary side capacitors of the compensation circuits, which create perfect resonance, are denoted as $C_{1}$ and $C_{2}$, respectively. In addition, the terms $I_{1}$ and $I_{2}$ denote the currents flowing through primary and secondary inductors.

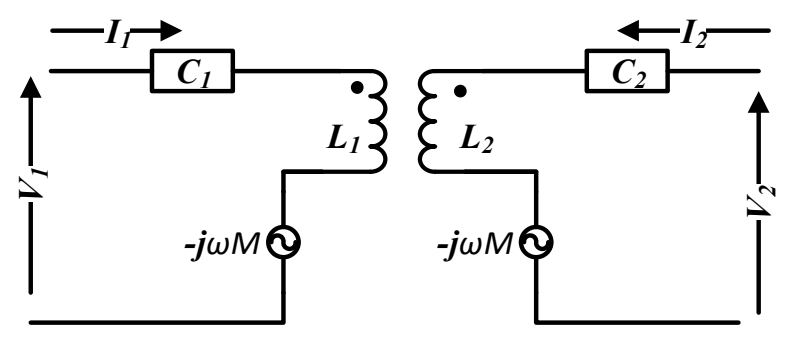

Figure 3. The simplified model of WPT system.

Based on the simplified model of the WPT system, input $V_{1}$ and output $V_{2}$ voltages are obtained as:

$$
\begin{aligned}
& V_{1}=Z_{1} I_{1}+j \omega L_{1} I_{1}+j \omega M I_{2} \\
& V_{2}=Z_{2} I_{2}+j \omega L_{2} I_{2}+j \omega M I_{1}
\end{aligned}
$$

where $\omega$ represents the angular frequency of the system, which maintains resonance and can be defined as:

$$
\omega=1 / \sqrt{C_{1} L_{1}}=1 / \sqrt{C_{2} L_{2}}
$$

Hence, these circuit parameters define the WPT system performance. 


\section{Coil Design and Simulation}

\subsection{Description of Coil Design}

Improvement of the power transfer efficiency of DWPT systems for EV charging is the focus of recent studies [1-5,13-48]. It was revealed that the efficiency depends significantly on the design of transmitting and receiving coils. Precisely, geometry, material, shielding and dimensions of coils as well as lateral and axial displacements between primary and secondary inductors drastically affect both self and mutual inductances. There are several methods commonly employed to estimate self-inductance $L$ of a coil and its quality factor $Q$, which were thoroughly described in [49-51]. However, while being of a key importance towards the enhancement of the DWPT system performance, the derivation of mutual inductance is a complicated procedure depending on many aspects. Thus, this section analyzes the factors which influence mutual inductance.

The literature review shows that various coil shapes have been analyzed and developed for the design of DWPT systems such as circular, rectangular, square, hexagonal, etc. [43,44,51-54]. However, Luo and Wei [54] claim that the circular and square shaped coil resonators are considered as basic geometries and therefore widely used. The inductively coupled area of square shaped coils is larger in comparing with circular shaped coils of the same size. However, the mutual inductance between the circular shaped coils is higher than between the square shaped coils [40].

Analytically, mutual inductance can be calculated using numerical iterations [55-57], look-up tables [57], Bessel and Struve functions [58], Heuman's lambda function [59], and Biot-Savart law [60]. However, with the development of computer aided tools based on the high precision Finite Element Analysis (FEA), the calculation of mutual inductance became simpler and more convenient. Hence, comparison of electromagnetic parameters of circular and square shaped coils was performed.

In addition, shielding of transmitter and receiver coils must be considered while designing a DWPT system. This is mainly required for safety reasons. Since the power is transferred at high frequencies (up to tens of $\mathrm{kHz}$ range) induction heating phenomena can occur [40]. In order to avoid this, ferrite bars or plates can be placed above the inductive coils. These would eliminate heating of the EV parts and could potentially increase mutual coupling between the coils by streamlining the magnetic flux through them. Moreover, these ferrite covers may be coated by a thin layer of aluminum, which will eliminate magnetic flux leakage [61]. However, analysis of the effects produced by a shielding material on mutual inductance is out of scope of this work.

Three cases comparing the performance of square and circular coils have been considered in this study. The first simulation was performed in order to identify self and mutual inductances for the proposed shapes under the condition that the conductor length for all the coils is kept constant. The second case is intended to estimate an optimized spacing $y$ between the lumped transmitter coils, as shown in Figure 4. The third simulation aims to demonstrate how mutual inductance is changed with respect to the lateral misalignment between the transmitter pads and the moving receiver coil. In all cases identical dimensions for transmitter and receiver coils were considered.

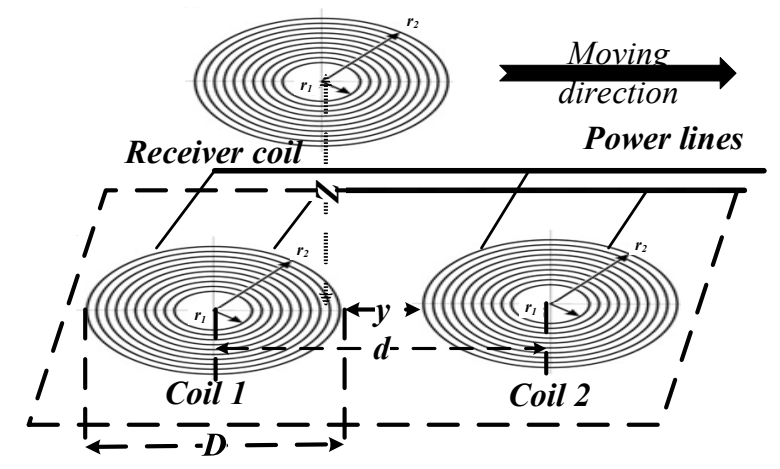

Figure 4. Schematic representation of transmitter and receiver coils. 


\subsection{Simulation Results and Analysis}

\subsubsection{Case 1: Comparison of Self and Mutual Inductances}

In order to compare the effectiveness of circular and square shaped coils, their self and mutual inductances were calculated. The copper cable with a $4 \mathrm{~mm}^{2}$ cross section was selected for the coils design. The vertical distance $Z$ between the transmitter coils and the moving pick-up coil is set constant, $65 \mathrm{~mm}$, for all three cases. The total length $\mathrm{L}$ of the conductor used for the design of the circular coil and square coils are $14.15 \mathrm{~m}$ and $14.6 \mathrm{~m}$, respectively, which are approximately the same. The number of turns for the transmitter $N_{1}$ and receiver $N_{2}$ coils is equal to 17 and 18, respectively. The circular coils' inner $r_{1}$ and outer $r_{2}$ radii are selected to be $106 \mathrm{~mm}$ and $156 \mathrm{~mm}$. On the other hand, the distance between the origin and the first turn of the square coils is equal to $106 \mathrm{~mm}$ and the length of each square coil is chosen to be $126 \mathrm{~mm}$. The 3-D models created in ANSYS Maxwell software for the two described shapes are illustrated in Figure 5a,b.

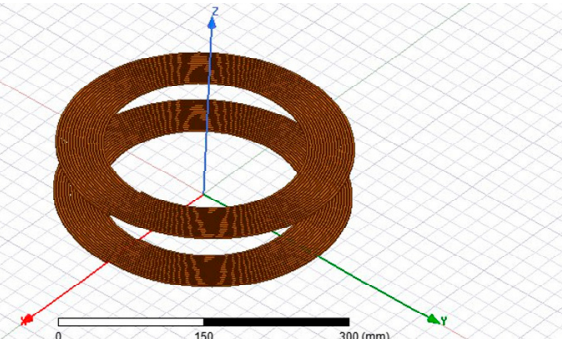

(a)

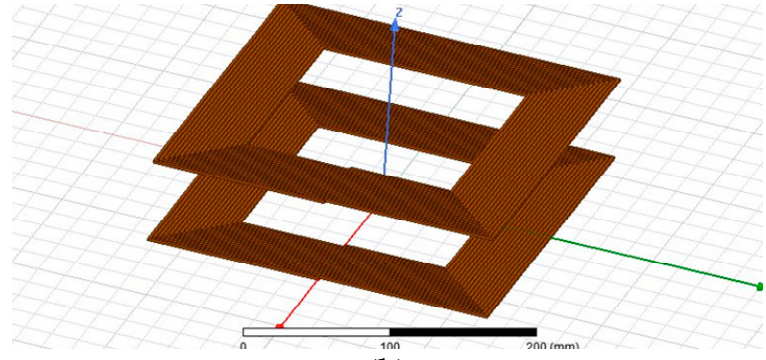

(b)

Figure 5. 3-D model representation of coils: (a) circular shape; (b) square shape.

According to the simulation results, the self-inductances $L_{1}$ and $L_{2}$ of the circular shaped coils are $115.714 \mu \mathrm{H}$ and $115.715 \mu \mathrm{H}$ respectively, while the corresponding values for the square shaped coils are $106.001 \mu \mathrm{H}$ and $106.027 \mu \mathrm{H}$. In addition, the mutual inductance between the transmitter and the receiver coils is equal to $40.068 \mu \mathrm{H}$ for the circular shape and $32.392 \mu \mathrm{H}$ for the square shape, respectively. Consequently, practical results have shown a theoretical prediction that the circular shaped coils have higher mutual inductance value than square shaped coils of the same size.

\subsubsection{Case 2: Identification of Proper Distance between Transmitter Coils}

In this simulation case, the effect of distance y between the two transmitter coils 1 and 2 on the mutual inductance of DWPT system is investigated. Particularly, the distance between the transmitters 1 and 2 is selected as $0 \%, 10 \%, 20 \%, 30 \%, 40 \%$ and $50 \%$ of either the circular coil's external diameter or the square coil's external width.

Figure 6 shows the effect of distance y on the mutual inductance for the circular shaped coils. It can be seen that the mutual inductance has the maximum value of $22.100 \mu \mathrm{H}$ when this distance is zero. As the distance between two transmitter coils increases, the mutual inductance decreases. The mutual inductance becomes approximately zero when the displacement between the transmitter coils is set to $160 \mathrm{~mm}$ ( $50 \%$ of the coil's diameter).

Figure 7 illustrates the correlation of the mutual inductance of the two square shaped transmitters with respect to the spacing between them. The general trend observed for the square shaped coils replicate the one produced by the circular transmitters. Precisely, as the distance between the two transmitting coils increases, the mutual inductance gradually reduces. Specifically, the highest value of mutual inductance which is equal to $23.783 \mu \mathrm{H}$ corresponds to the no distance (zero) between the transmitters, whereas the lowest value of $2.084 \mu \mathrm{H}$ was recorded at the $126 \mathrm{~mm}$ displacement. 


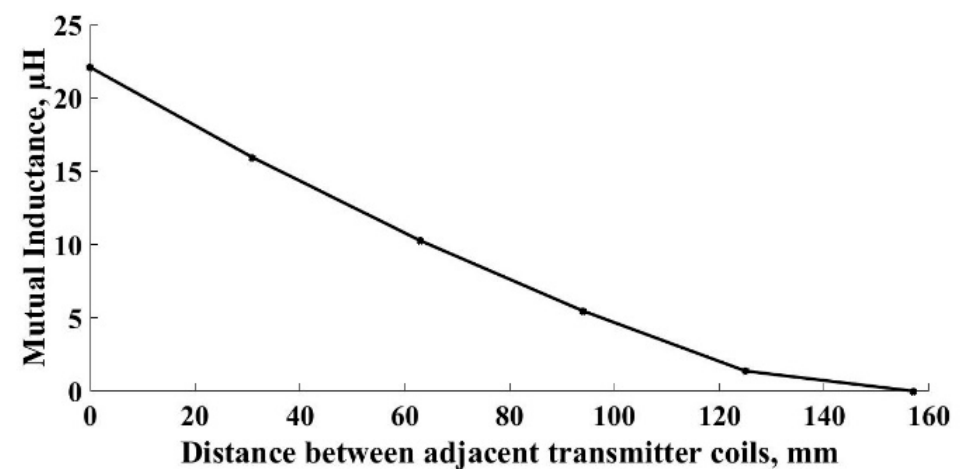

Figure 6. Effect of displacement between transmitters on the mutual inductance for circular shaped coils.

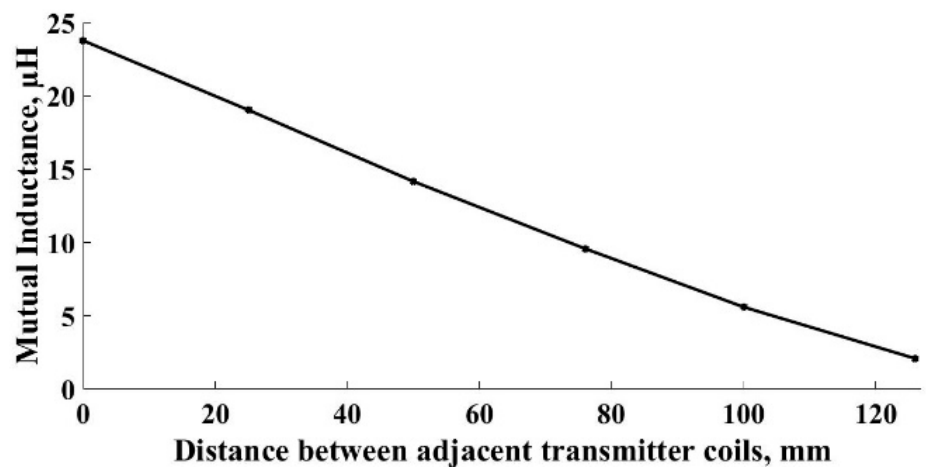

Figure 7. Effect of displacement between transmitters on the mutual inductance for square shaped coils.

By comparing simulation results for the circular and square shaped coils, it was revealed that the mutual inductance between the transmitters and receiver is slightly higher in case of the square shaped coils than in circular shaped coils. This can be explained by the fact that the inductive area of the square shaped coil is larger than that of the circular shaped coils.

For instance, when the second square shaped transmitter coil is located $126 \mathrm{~mm}$ (50\% of square's side length) apart from the first square shaped transmitter coil, the mutual inductance is equal to $1.371 \mu \mathrm{H}$. On the other hand, for the circular shaped coils separated by the $157 \mathrm{~mm}(50 \%$ of coil's diameter) it is equal to zero. Furthermore, the optimal value of mutual inductance is achieved when the displacement between the adjacent coils equals to $20 \%$ of diameter (width) for both shapes. The values of mutual inductance in that case are estimated to be $10.265 \mu \mathrm{H}$ and $14.172 \mu \mathrm{H}$ for circular and square shaped coil, respectively. Consequently, this spacing as well as corresponding induction values were selected for further simulation and analysis.

\subsubsection{Case 3: Observation of Mutual Inductance Change with Respect to Lateral Misalignment}

The 3-D view of the circular shaped coils is presented in Figure 8a. There are two transmitter coils, which are $63 \mathrm{~mm}$ apart from each other and a receiver coil situated at a constant $65 \mathrm{~mm}$ distance above. In order to analyze the effect of the moving receiver on the mutual inductance between the coils, the pick-up (receiver) coil is driven along the $Y$-axis and the mutual inductances between the transmitter and the receiver are calculated. Figure $8 \mathrm{~b}$ presents the simulation results. As it can be observed, generally, the mutual inductance can be enhanced by increasing the number of transmitter coils. 


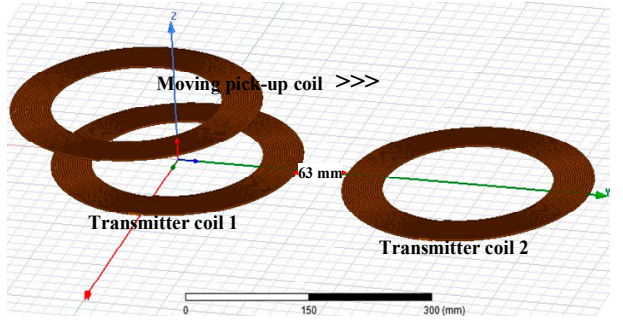

(a)

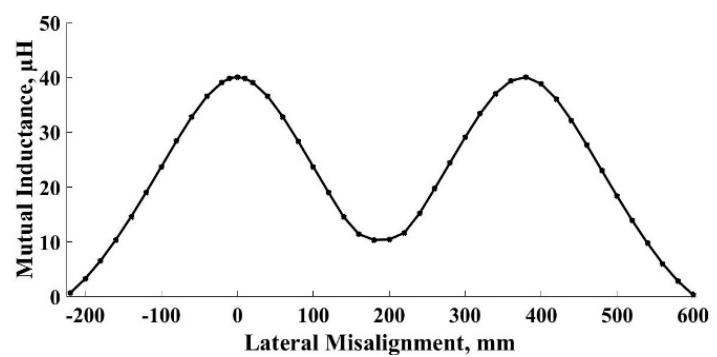

(b)

Figure 8. (a) 3-D view of circular shaped coils; (b) Plot of mutual inductance change with respect to lateral misalignment.

The first position of the receiver coil center was at $-220 \mathrm{~mm}$ apart from the first transmitter coil's center since at this distance magnetic coupling initially occurs. The mutual inductance value is the smallest at this point and equal to $0.686 \mu \mathrm{H}$. Then, by moving the receiver coil forward, the mutual inductance value increases and reaches its maximum value at the perfect alignment between the first transmitter coil and the receiver coil. Precisely, the mutual inductance equals to $40.096 \mu \mathrm{H}$ when the lateral misalignment between the coils' centers becomes zero. This value reoccurs in case of the perfect alignment of the pick-up coil with the second transmitter coil.

Following the circular coils' model, the same scenario was modelled for the square shaped coils as demonstrated in Figure 9a. Similarly, this simulation was performed to identify the change in mutual inductance with respect to the lateral misalignment. For square coils, the receiver coil center was moved to $-190 \mathrm{~mm}$ distance from the first transmitter coil center. The mutual inductance at this point was found to be the lowest and equal to $1.114 \mu \mathrm{H}$. In addition, an increasing trend for mutual inductance values can be observed from the farthermost distance to zero of misalignment, as shown in Figure $9 \mathrm{~b}$. At perfect alignment position between the receiver coil and two transmitter coils, the mutual inductance has the highest values estimated at $33.072 \mu \mathrm{H}$ and $32.348 \mu \mathrm{H}$, respectively. However, when the receiver coil moves from the first transmitter coil to the second transmitter coil and becomes $150 \mathrm{~mm}$ apart from both transmitters, the mutual inductance decreases and reaches the minimum value of $13.924 \mu \mathrm{H}$.

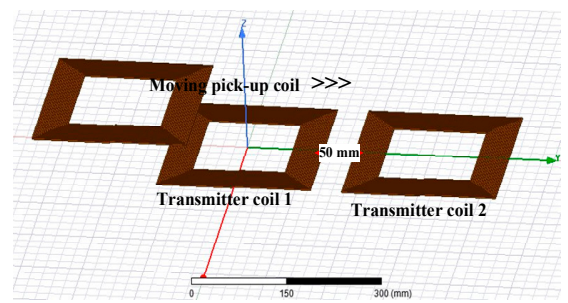

(a)

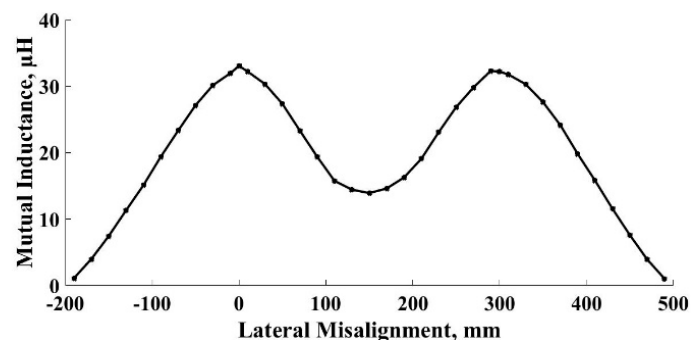

(b)

Figure 9. (a) 3-D view of square shaped coils; (b) Plot of mutual inductance change with respect to lateral misalignment.

The mutual inductance at perfect alignment position is higher in the circular shaped coils than in square shaped coils. The scope of this study covers the analysis of the effect of variable mutual inductance on the system's efficiency. Therefore, based on the presented simulation results, circular shaped coils were selected for the analysis of the whole DWPT system performance. However, before conducting dynamic WPT simulation study and analyzing DWC output power; it was required that the dynamic mutual inductance be examined practically. 


\section{Practical Study on Variable Mutual Inductance}

This section compares simulation and experiment results over the change of the mutual inductance with respect to the lateral misalignment. Section 4.1 introduces a practical method for measuring mutual inductance. Section 4.2 presents and compares simulation and experimental results. Firstly, mutual inductance is determined between one transmitter and one receiver coil, and secondly, between two transmitters and one receiver coil.

\subsection{Method for Measuring Mutual Inductance}

For the mutual inductance measurement between two coils, they are connected in series. Then, the self-inductance of the combination is measured and, using that value, mutual inductance between these coils is calculated. Consider two coils connected in series with self-inductances $L_{1}$ and $L_{2}$ coupled with magnetic fields in one direction (Figure 10).

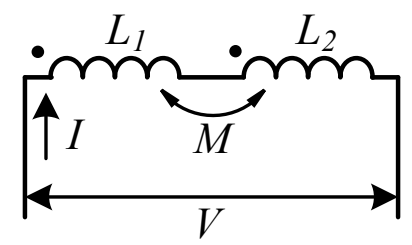

Figure 10. Two coils connected in series with magnetic fields in one direction.

Suppose there is a current injected into this series combination. The total induced voltage due to this current across the series combination is:

$$
V=V_{1}+V_{M, 1}+V_{2}+V_{M, 2}
$$

where, $V_{1}$ and $V_{2}$ are voltages induced by $L_{1}$ and $L_{2}$, respectively. $V_{M, 1}$ and $V_{M, 2}$ are voltages induced by $M$ in these two coils. They have positive sign due to aiding magnetic fields. Since the current flowing through the coils is the same, $V_{M, 1}$ and $V_{M, 2}$ are equal. If the current flowing through coils is $I$ and the induced electromotive force (EMF) by Lenz's law is $-L d I / d t$, then the expression (4) becomes:

$$
\begin{gathered}
V=-L_{1} d I / d t-M d I / d t-L_{2} d I / d t-M d I / d t \\
=-\left(L_{1}+L_{2}+2 M\right) d I / d t
\end{gathered}
$$

Therefore, the total self-inductance $L$ is:

$$
L=L_{1}+L_{2}+2 M
$$

If $L, L_{1}$ and $L_{2}$ are known, then the mutual inductance $M$ can be obtained as:

$$
M=\left[L-\left(L_{1}+L_{2}\right)\right] / 2
$$

\subsection{Simulation and Experiment Results}

Coils for the experiment are spiral planar coils constructed using AWG 8 type of conductor with 100 feet $(30.5 \mathrm{~m})$ length. This length was adequate to construct two coils with self-inductance of about $90 \mu \mathrm{H}$ each. Dimension parameters of two coils are shown in Table 1.

Figure 11a,b show isometric and top views of the coils in perfect alignment in simulation, respectively. Figure 12 shows two experimental coils in perfect alignment and industrial high performance equipment. The vertical distance between two coils was retained at $6 \mathrm{~cm}$. These two coils were connected in series and current source of measurement device with constant 6 A was utilized to measure the self-inductance values. 
Table 1. Transmitter and receiver coil parameters.

\begin{tabular}{ll}
\hline Parameter & Transmitter \& Receiver Coils \\
\hline Number of turns & 18 \\
Inner diameter & $140 \mathrm{~mm}$ \\
Conductor diameter & $4 \mathrm{~mm}$ \\
Turn spacing & $3 \mathrm{~mm}$ \\
Outer diameter & $400 \mathrm{~mm}$ \\
\hline
\end{tabular}

Before measuring the mutual inductance, self-inductances of each coil are measured and compared with the simulation, see Table 2. Experimental measurements of self-inductances revealed larger values compared to the simulation study due to additional wirings which were used for the connection with the measurement equipment.
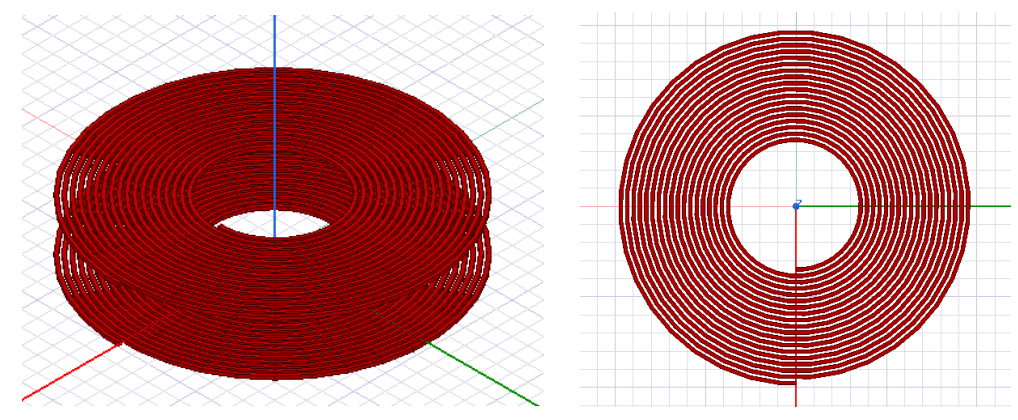

Figure 11. Simulation (two coils in perfect alignment): (Left) isometric view and (Right) top view.

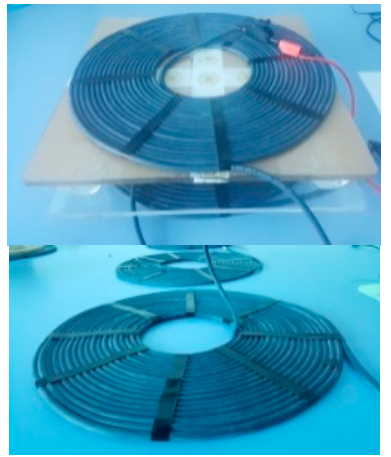

(a)

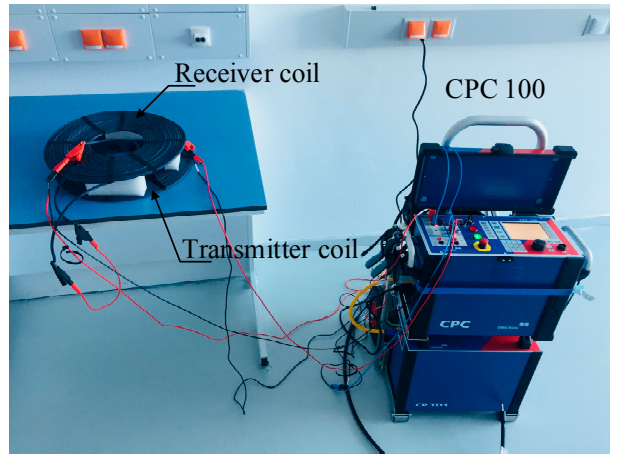

(b)

Figure 12. Experimental setup, (a) sliding setup for transmitter and receiver; (b) measurement equipment.

Table 2. Transmitter and receiver coil self-inductances.

\begin{tabular}{lcc}
\hline Coil Type & Simulation Results & Experiment Results \\
\hline Transmitter coil & $86.8 \mu \mathrm{H}$ & $93.4 \mu \mathrm{H}$ \\
Receiver coil & $86.8 \mu \mathrm{H}$ & $90.7 \mu \mathrm{H}$ \\
\hline
\end{tabular}

For the simulation and practical measurements, it is assumed that the transmitter coil lies in $X Y$ plane with its center at $(0,0,0)$ in $X Y Z$ coordinate system, while the receiver coil center coordinates are changed along $Y$ axis from $(0,-50 \mathrm{~cm}, 6 \mathrm{~cm})$ to $(0,50 \mathrm{~cm}, 6 \mathrm{~cm})$ by an increment of $10 \mathrm{~cm}$. There is no angular misalignment, i.e., transmitter and receiver coil planes are parallel physically in all measurements. Coils are connected in series and self-inductance of the combination for each position is determined. Finally, mutual inductance is calculated using (7). 
Table 3 provides mutual inductance values for different positions found by experiment and by simulation. Position 6 is the case when center coordinates of both coils are $(0,0,0)$, i.e., they are in perfect alignment.

Table 3. Simulation and experiment results.

\begin{tabular}{llll}
\hline Position Number & $\begin{array}{l}\text { Receiver Coil Center } \\
\text { Coordinates, } \mathbf{c m}\end{array}$ & $\begin{array}{l}\text { Mutual Inductance } \\
\text { (Experiment), } \boldsymbol{\mu H}\end{array}$ & $\begin{array}{l}\text { Mutual Inductance } \\
\text { (Simulation), } \boldsymbol{\mu H}\end{array}$ \\
\hline 1 & $(0,-50,6)$ & 1.30 & 1.10 \\
2 & $(0,-40,6)$ & 2.70 & 2.22 \\
3 & $(0,-30,6)$ & 3.05 & 2.65 \\
4 & $(0,-20,6)$ & 4.70 & 6.63 \\
5 & $(0,-10,6)$ & 28.2 & 27.8 \\
6 & $(0,0,6)$ & 40 & 40.96 \\
7 & $(0,10,6)$ & 29.4 & 27.8 \\
8 & $(0,20,6)$ & 6.35 & 6.62 \\
9 & $(0,30,6)$ & 3.75 & 2.65 \\
10 & $(0,40,6)$ & 3.15 & 2.22 \\
11 & $(0,50,6)$ & 2.20 & 1.10 \\
\hline
\end{tabular}

Figure 13 shows experimental and simulation graphs of the mutual inductance with respect to the $Y$ coordinate of the center of the receiver coil.

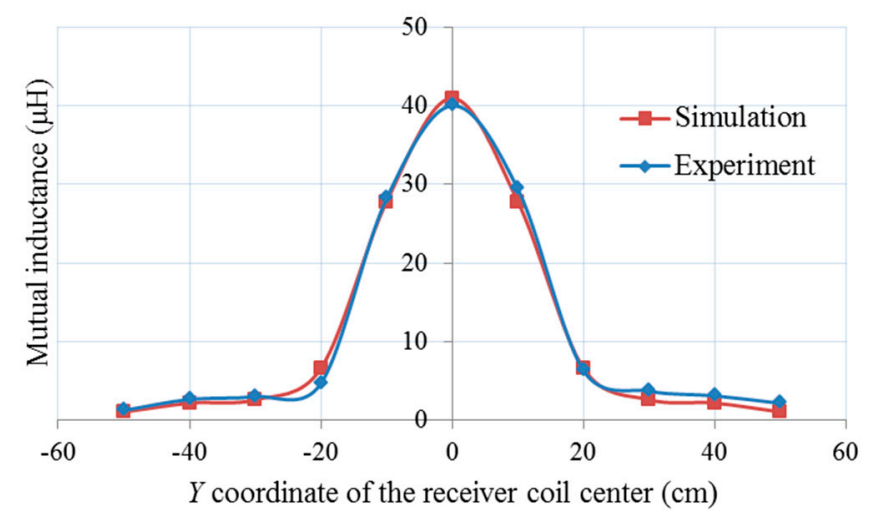

Figure 13. Mutual inductance vs. $Y$ coordinate of the receiver coil center.

Both simulation and experiment results are in good agreement. Mutual inductance is maximum in perfect alignment, being about $40 \mu \mathrm{H}$ and $41 \mu \mathrm{H}$ for the experiment and simulation, respectively. Mutual inductance decreases at a very fast rate when misalignment between coils increases, and, after the center of the receiver coil coincides with the edge of the transmitter coil, it decreases at a much slower rate.

For the case with two transmitters and one receiver with dimensions similar as in Table 1 for all three coils and with relative position as in Figure 8a, two mutual inductances exist (ignoring the one between transmitters): one between the coil 1 and the receiver $\left(M_{13}\right)$, and another between the coil 2 and the receiver $\left(M_{23}\right)$. The behavior of each of these mutual inductances with respect to the relative receiver coil position is similar to that of Figure 13 and is shown in Figure 14. In this case, transmitter coils 1 and 2 have center coordinates at $(0,0,0)$ and $(0,50 \mathrm{~cm}, 0)$, respectively. As noticed, $M_{23}$ behavior is similar to $M_{13}$ with the peak being at the time when receiver coil center is at $(0,50 \mathrm{~cm}, 6 \mathrm{~cm})$, i.e., when transmitter coil 2 and receiver coil are in perfect alignment. 


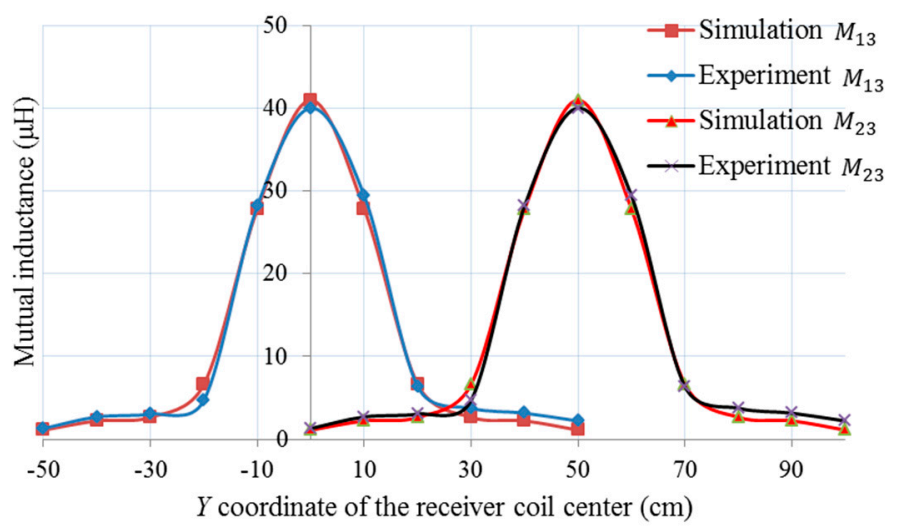

Figure 14. Mutual inductance $M_{13}$ and $M_{23}$.

However, if transmitter coils are considered as one coil, i.e., when they are connected in parallel and the same current $I$ flows through each coil due to their identical parameters (as in Figure 15), then the voltage induced in the receiver is:

$$
V_{\text {ind }}=-L_{3} d I_{r} / d t-\left(M_{13}+M_{23}\right) d I / d t
$$

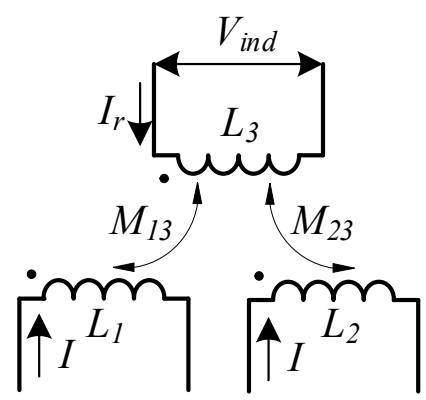

Figure 15. Mutual inductance between two transmitters and one receiver vs. $X$ coordinate of the receiver coil center.

In (8), the first term of the sum indicates the self-induced EMF, while the second term indicates the EMF induced by mutual coupling of the receiver coil with two transmitter coils. Thus, the total mutual inductance, representing the coupling of the receiver with both transmitters connected in parallel is $M=M_{13}+M_{23}$. Then, the behavior of $M$ is as in Figure 16 .

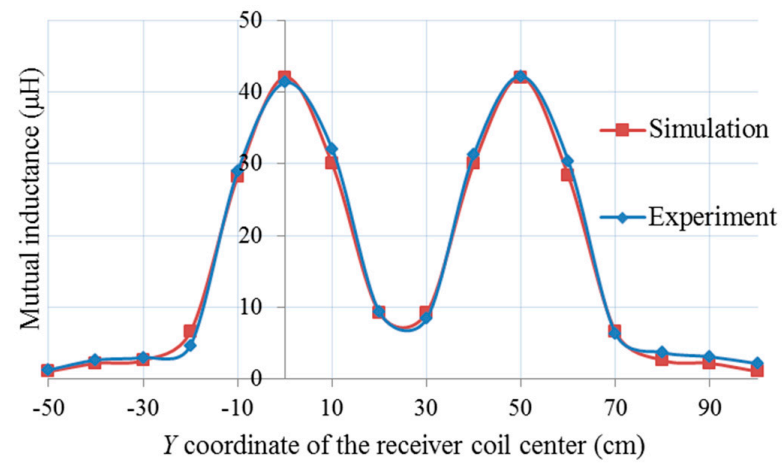

Figure 16. Mutual inductance between two transmitters and one receiver vs. $X$ coordinate of the receiver coil center. 
Results of the experiment are almost in a perfect agreement with the results of the simulation. This suggests that the method proposed for measuring the variable mutual inductance is accurate. These results can further be significantly useful in simulating dynamic WPT system and predicting the behavior of the system voltage, current and output power waveforms.

\section{Dynamic WPT Simulation}

\subsection{DWPT Simulation}

The proposed DWPT system for EV charging was modeled and simulated in order to analyze system performance in terms of efficiency. The created model is based on the layout depicted in Figure 2 explained earlier. It is supplied by a DC input voltage of $100 \mathrm{~V}$, which is then converted to the square wave $\mathrm{AC}$ voltage changing between $+100 \mathrm{~V}$ and $-100 \mathrm{~V}$. The fundamental frequency of this system is set to be $85 \mathrm{kHz}$. Other system parameters are listed in Table 4. The coils' geometry, self and mutual inductance values are obtained from ANSYS Maxwell simulation results, whereas other values of the circuit elements are assumed as in [62].

Table 4. Parameters of the proposed DWPT system.

\begin{tabular}{ll}
\hline Parameter & Value \\
\hline$L_{1 t}, L_{2 t}, L_{1 r}$ & $115.4 \mu \mathrm{H}, 115.5 \mu \mathrm{H}, 115.4 \mu \mathrm{H}$ \\
$R_{1 t}, R_{2 t}, R_{1 r}$ & $60 \mathrm{~m} \Omega, 60 \mathrm{~m} \Omega, 60 \mathrm{~m} \Omega$ \\
$C_{1 t}, C_{2 t}, C_{1 r}$ & $190 \mathrm{pF}, 190 \mathrm{pF}, 43 \mathrm{pF}$ \\
$L_{t 1}, L_{t 2}$ & $40 \mu \mathrm{H}, 40 \mu \mathrm{H}$ \\
$R_{t 1}, R_{t 2}$ & $12 \mathrm{~m} \Omega, 12 \mathrm{~m} \Omega$ \\
$C_{t 1}, C_{t 2}$ & $190 \mathrm{pF}, 190 \mathrm{pF}$ \\
$R_{1}, R_{2}$ & $12 \mathrm{~m} \Omega, 12 \mathrm{~m} \Omega$ \\
$C_{1}, C_{2}$ & $260 \mathrm{pF}, 260 \mathrm{pF}$ \\
$M_{1}, M_{2}, M_{12}$ & $40 \mu \mathrm{H}, 40 \mu \mathrm{H}, 2.3 \mu \mathrm{H}$ \\
$R_{L}$ & $15 \Omega$ \\
\hline
\end{tabular}

Two simulation scenarios were performed for the verification of the proposed model. Under the first scenario, three switching cases were examined. Transmitter coils are turned on or off at various instances via the switches $S_{11}$ and $S_{22}$, as shown in Table 5. The time interval between the case transitions is selected arbitrarily and assumed as $30 \mathrm{~ms}$. It should be noted that, when the transmitter coil is active, its mutual inductance with the vehicle-side coil is $40 \mu \mathrm{H}$ in all three cases. For instance, in case 2 both transmitter coils, each having $40 \mu \mathrm{H}$ mutual inductance value, will be coupled with the receiver coil for $30 \mathrm{~ms}$, whereas in cases 1 and 3 only one transmitter coil with $40 \mu \mathrm{H}$ mutual inductance is energized.

Table 5. Specifications of simulation cases.

\begin{tabular}{lll}
\hline Case & Switches ON & Time Duration \\
\hline 1 & $S_{11}$ & $0-30 \mathrm{~ms}$ \\
2 & $S_{11}$ and $S_{22}$ & $30 \mathrm{~ms}-60 \mathrm{~ms}$ \\
3 & $S_{22}$ & $60 \mathrm{~ms}-90 \mathrm{~ms}$ \\
\hline
\end{tabular}

The input currents $I_{t 1}, I_{t 2}$ flowing from the inverter output are shown in Figure 17a-d. It can be observed from Figure 17a, $I_{t 1}$ in case 1 has a stable value which is equal to $40 \mathrm{~A}$, but in case 2 this current has decreased to $37 \mathrm{~A}$. It is decreased due to switch on of the second switch and the input current from the inverter is distributed between the two transmitter coils. The reverse situation can be seen in Figure 17c, the current $I_{t 2}$ is initially equal to zero and starts to increase to approximately $75 \mathrm{~A}$ in case 2 . In case $3, I_{t 2}$ becomes higher since all the input current is flowing through the second transmitter coil. Moreover, the nature of these curves is the sinusoidal curve as shown in Figure $17 \mathrm{~b}$, d for the currents $I_{t 1}, I_{t 2}$, respectively. 
These graphs are the large scale views of the corresponding currents at the instant when transmitter coil 1 becomes de-energized (at $0.06 \mathrm{~s}$ ). At $0.06 \mathrm{~s}, I_{t 1}$ immediately reaches zero because an open circuit is created, while a transient is created in the $I_{t 2}$ waveform which stabilizes after some amount of time.

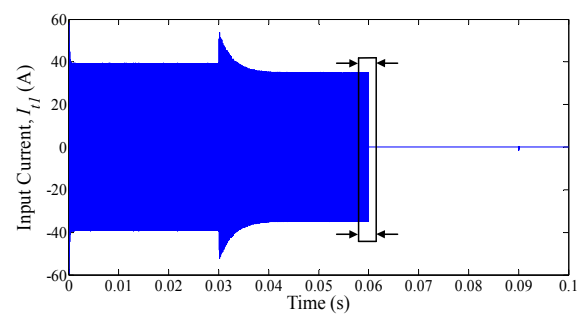

(a)

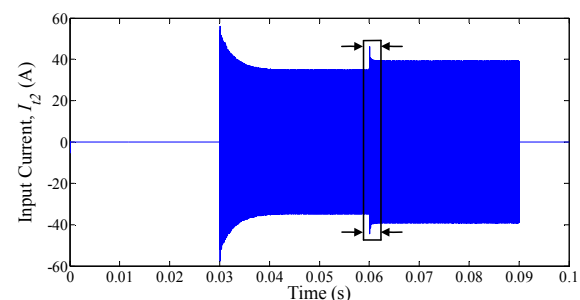

(c)

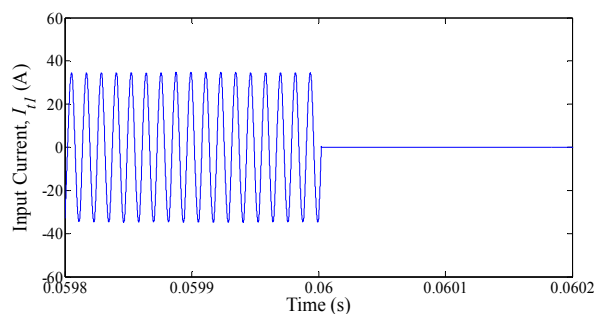

(b)

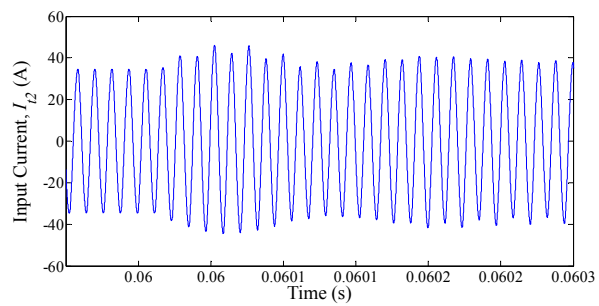

(d)

Figure 17. Simulation results for: (a) Input current of transmitter $1, I_{t 1} ;(\mathbf{b})$ large scale view of $I_{t 1}$ when coil 1 turns off; (c) Input current of transmitter $2, I_{t 2}$; (d) large scale view of $I_{t 2}$ when coil 1 turns off.

Simulation results for the currents flowing through the first and the second transmitter coils $I_{1}, I_{2}$ as well as through the receiver coil $I_{L}$ are presented in Figure 18a-f.

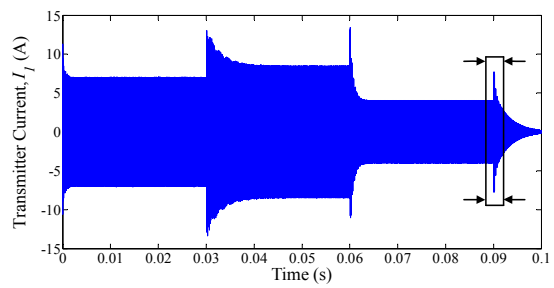

(a)

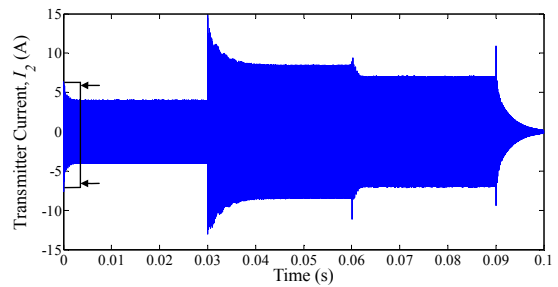

(c)

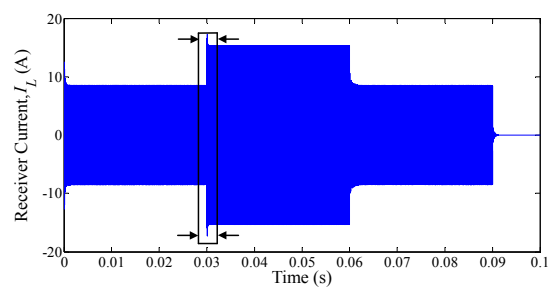

(e)

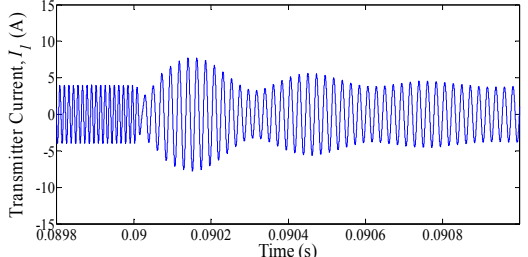

(b)

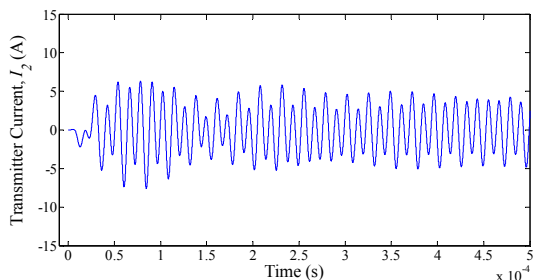

(d)

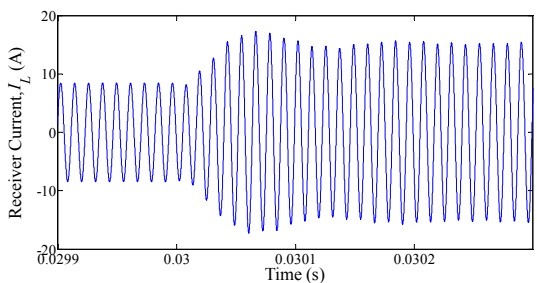

(f)

Figure 18. Simulation results for: (a) Current through first transmitter coil, $I_{1} ;(\mathbf{b})$ large scale view of $I_{1}$ when both coils are off; (c) Current through second transmitter coil, $I_{2} ;(\mathbf{d})$ large scale view of $I_{2}$ when coil1 turns on; (e) Current through receiver, $I_{L} ;$ (f) large scale view of $I_{L}$ when coil 2 turns on. 
Figure 18a-d show the waveforms of the simulated currents $I_{1}$ and $I_{2}$, which flow through $L_{1 t}$ and $L_{2 t}$. coils, respectively. In case 1 , only the switch $S_{11}$ is activated; thus, the total input current of $6.75 \mathrm{~A}$ is supplied to the first ground-side coil from 0 until $30 \mathrm{~ms}$. In case 2, both currents $I_{1}$ and $I_{2}$ become $8.2 \mathrm{~A}$. This is caused by activating both switches $S_{11}$ and $S_{22}$, which has resulted to the equal distribution of input current between two ground-sided coils. Similar behavior to case 1 is observed for current $I_{2}$ in case 3. Precisely, the entire input current is solely delivered to the second transmitter coil. This is explained by the fact that only $S_{22}$ switch is in operation for the case 3. Also, current $I_{1}$ must equal to zero in case 3 and current $I_{2}$ must equal to 0 in case 1 . Moreover, current transients are observed between the case transitions. They can be caused by the switching operation between transmitter coils. Large scale views of some of these transients are shown as an example in Figure 18b,d,f. These transients have different time of stabilization for different cases. For instance, it took about $1 \mathrm{~ms}$ for both currents $I_{1}, I_{2}$ to reach a steady state from case 1 to case 2 , and about $1 \mu$ s from case 2 to case 3 .

Figure 18e-f represent the behavior of the current $I_{L}$, which is delivered to the receiver coil $L_{1 r}$. The stable current of $9 \mathrm{~A}$ is flowing through the receiver coil in cases 1 and 3 . However, it is observed that in case $2, I_{L}$ is higher than in other cases and equals to approximately $15 \mathrm{~A}$. This is because both transmitters coils are energized in case 2 and transmit power to the receiver.

In simulations performed above, three positions of the receiving coil with respect to the primary-side transmitter coils have been considered. In cases 1 and 3 , the receiver coils were positioned in perfect alignment with transmitter coils 1 and 2, respectively. In case 2, the pick-up coil was in perfect alignment state with both transmitters simultaneously, hence the higher values of currents are observed. However, the conditions maintained for the case 2 are unrealistic. In other words, when the receiver coil moves from the first transmitter to the second transmitter, the coupling will become weaker and the mutual inductance will decrease. Consequently, it will cause a significant drop in the delivered current.

Thus, the performance of the dynamic WPT system was further examined employing the second simulation scenario. According to the simulation setup for planar circular-shaped coils presented in Section 3, the mutual inductance values were obtained by changing the lateral misalignment between the transmitter coils and the receiver coil from $-220 \mathrm{~mm}$ to $600 \mathrm{~mm}$ interval. The function using the values of the mutual inductance with respect to the lateral misalignment is created. Then, this function along with controlled voltage sources are used to simulate variable EMFs induced in the transmitter and receiver coils. Knowing that the total distance that the EV travels over the two transmitters is equal to $880 \mathrm{~mm}$ and assuming its average speed is $20 \mathrm{~m} / \mathrm{s}$, the entire passing time will result in $40 \mathrm{~ms}$. The simulation result for the dynamic change of the current $I_{L}$ with respect to the EV's travelling time is shown in Figure 19.

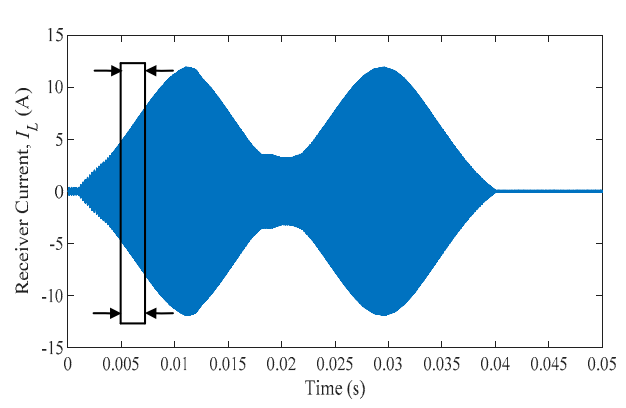

(a)

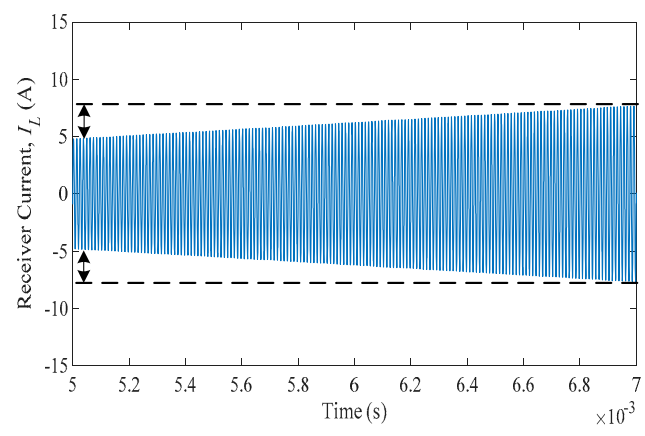

(b)

Figure 19. Simulation results for: (a) of $I_{L}$ current; (b) large scale view between time intervals of $0.005-0.007 \mathrm{~s}$.

Considering Figure 19, the moving power pick-up coil is coupled with the first transmitter only from 0 to $19 \mathrm{~ms}$, whereas with the second transmitter from $22.857 \mathrm{~ms}$ to $40 \mathrm{~ms}$. In the time interval 
between $19 \mathrm{~ms}$ up to $22.857 \mathrm{~ms}$, the receiver coil is coupled with both transmitter coils simultaneously. The maximum values of $I_{L}$ are achieved at $11.429 \mathrm{~ms}$ and $29.524 \mathrm{~ms}$, when the receiver is in perfect alignment with the first and the second transmitters, respectively. As the EV begins the motion, it drives over the first transmitter coil. At the same time, the current starts to grow, peaks at zero lateral misalignment and, after that, it decreases again (see Figure 19). The same behavior is observed in case when the receiver moves over the second transmitter coil.

\subsection{Short Discussion}

An effect of varying mutual inductance on the system output power is presented in Figure 20. The values of the mutual inductances were taken from simulation results produced in simulator (Section 3). The maximum power of $1.7 \mathrm{~kW}$ is achieved when the receiver coil is in perfect alignment state with one of the two transmitter coils, whereas the input power was $1.8 \mathrm{~kW}$.

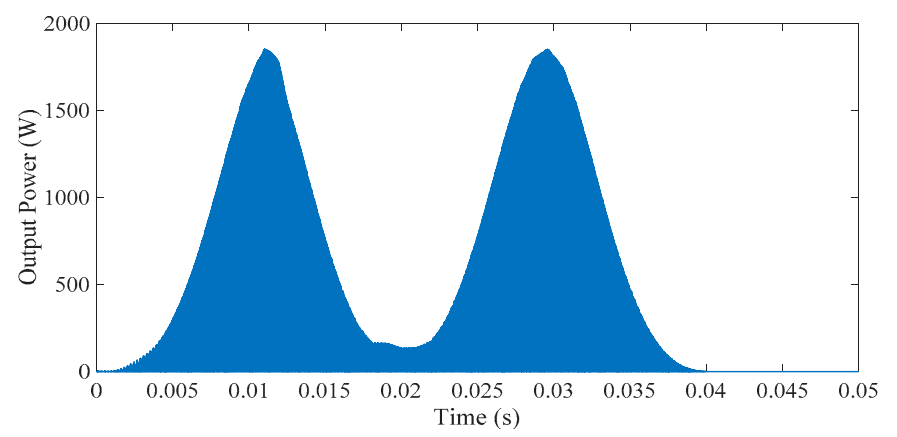

Figure 20. The output power of proposed DWPT system for the second simulation scenario.

According to Figure 20, the higher the misalignment between the coils, the lower is the output power. Indeed, the output power value is proportional and dependent on the mutual inductance value. The peak value for output power is obtained where the mutual inductance shows its maximum value.

\section{Conclusions}

In this study, the dynamic mutual inductance in a DWPT system was introduced. The pulsation problem in the output current and power profile were discussed in detail. It was highlighted that one of the reasons causing undesirable pulsation in DWPT is the dynamic mutual inductance once the vehicle is in motion. This inductance comes through the shape of transmitter and receiver coils as well as the horizontal arrangement and spacing between the transmitter coils. Furthermore, in a deep analysis, the circular and square shaped coils were model and simulated and advantages and disadvantage of each coil in mutual inductance value and its variation were studied. Dynamic mutual inductance profiles for both coils were calculated, plotted and analyzed. It was shown that for a similar coil conductor length, the circular transmitter and receiver coils provide more mutual inductance in full alignment condition, approximately $18 \%$ more than rectangle coils for a case we studied; however, rectangular coils cause less pulsation. This part was supported through coils' fabrication and practical measurement once the receiving coil slides and moving forward over the transmitter coil. Practical results confirmed the results obtained via simulation study. A dynamic WPT system for EV charging was then modeled and simulated using data obtained through practical measurements. The currents flowing through the transmitter and receiver coils as well as output power were simulated through different scenarios. It was shown that the output power decreases with the increase in lateral misalignment between the transmitter and receiver coils. In addition, the system's output characteristics are significantly influenced by the degree of coupling between the transferring and receiving coils. The results revealed that a careful design and spacing of transmitter and receiver coils are required to reach an efficient EV 
charging arrangement and pulsation reduction. One possible solution can be implementing circular coils with reducing the transmitter coils spacing.

In DWC, there are several challenges that need to be addressed, and require further exploration as future work. Firstly, the power pulsation at the receiver side during motion has an adverse effect on the storage system and corresponding electronic components. Therefore, it is necessary to minimize such pulsation and fluctuation; this can be obtained through several solutions. One of the approaches involves appropriate design of transmitter and receiver coils. For instance, it is noted that rectangular-shaped coils create less power pulsations due to their geometric structure; therefore, the optimal design of a rectangular-shaped coil should be developed. Another approach includes designing the battery charging circuit to provide a relatively smooth output to the battery unit. Secondly, the speed of charging of storage units is a substantial challenge, particularly in DWPT. One of the possible solutions can be the complementary use of supercapacitors and batteries, as supercapacitors have rapid charge and discharge characteristics. Thirdly, the effects of the ferrite or metallic shields on mutual inductance should be considered, as this can minimize the leakage flux, and increase mutual coupling between transmitter and receiver coils. Additionally, in future it will be highly important to design the switching algorithm of transmitter coils according to the position of the multiple receivers; this will allow more energy-savings. Potentially, this can be achieved using time-sharing and beamforming techniques. In time-sharing, only a certain group of receivers is energized in a specific timeframe. This allows an optimal wireless power distribution to multiple users, thus receiver which is relatively far from the transmitter coil has a longer timeframe. In beamforming, a magnetic field from all transmitter coils is combined in a certain beam, which strengthens the power transfer to the specific receiver. Similarly, beamforming can be used for WPT to the receivers which are relatively far from transmitter coils.

Author Contributions: All authors contributed equally.

Conflicts of Interest: The authors declare no conflict of interest.

\section{References}

1. Mi, C.C.; Buja, G.; Choi, S.Y.; Rim, C.T. Modern Advances in Wireless Power Transfer Systems for Roadway Powered Electric Vehicles. IEEE Trans. Ind. Electron. 2016, 63, 6533-6545. [CrossRef]

2. Choi, S.Y.; Gu, B.W.; Jeong, S.Y.; Rim, C.T. Advances in Wireless Power Transfer Systems for Roadway-Powered Electric Vehicles. IEEE J. Emerg. Sel. Top. Power Electron. 2015, 3, 18-36. [CrossRef]

3. Suh, I.-S.; Kim, J. Electric vehicle on-road dynamic charging system with wireless power transfer technology. In Proceedings of the 2013 International Electric Machines \& Drives Conference, Chicago, IL, USA, 12-15 May 2013; pp. 234-240. [CrossRef]

4. Buja, G.; Bertoluzzo, M.; Dashora, H.K. Lumped Track Layout Design for Dynamic Wireless Charging of Electric Vehicles. IEEE Trans. Ind. Electron. 2016, 63, 6631-6640. [CrossRef]

5. Platt, J. IEEE-USA Today's Engineer. Available online: http://te.ieeeusa.org/2010/Aug/electric-vehicles.asp (accessed on 18 November 2017).

6. Hu, X.; Murgovski, N.; Johannesson, L.M.; Egardt, B. Optimal Dimensioning and Power Management of a Fuel Cell/Battery Hybrid Bus via Convex Programming. IEEE/ASME Trans. Mechatron. 2015, 20, 457-468. [CrossRef]

7. Hu, X.; Li, S.E.; Yang, Y. Advanced Machine Learning Approach for Lithium-Ion Battery State Estimation in Electric Vehicles. IEEE Trans. Transp. Electrif. 2016, 2, 140-149. [CrossRef]

8. Hu, X.; Zou, C.; Zhang, C.; Li, Y. Technological Developments in Batteries: A Survey of Principal Roles, Types, and Management Needs. IEEE Power Energy Mag. 2017, 15, 20-31. [CrossRef]

9. Sallan, J.; Villa, J.; Llombart, A.; Sanz, J. Optimal Design of ICPT Systems Applied to Electric Vehicle Battery Charge. IEEE Trans. Ind. Electron. 2009, 56, 2140-2149. [CrossRef]

10. Covic, G.A.; Boys, J.T. Modern Trends in Inductive Power Transfer for Transportation Applications. IEEE J. Emerg. Sel. Top. Power Electron. 2013, 1, 28-41. [CrossRef] 
11. Sanchez-Sutil, F.; Hernandez, J.C.; Tobajas, C. Overview of Electrical Protection Requirements for Integration of a Smart DC Node with Bidirectional Electric Vehicle Charging Stations into Existing AC and DC Railway Grids. Electr. Power Syst. Res. 2015, 122, 104-118. [CrossRef]

12. Hernandez, J.C.; Sutil, F.S.; Vidal, P.G. Protection of a Multiterminal DC Compact Node Feeding Electric Vehicles On Electric Railway Syst. Secondary Distribution Networks, and PV Systems. Turk. J. Electr. Eng. Comput. Sci. 2016, 24, 3123-3143. [CrossRef]

13. Zhang, W.; Wong, S.-C.; Tse, C.K.; Chen, Q. An Optimized Track Length in Roadway Inductive Power Transfer Systems. IEEE J. Emerg. Sel. Top. Power Electron. 2014, 2, 598-608. [CrossRef]

14. Waffenschmidt, E.; Staring, T. Limitation of inductive power transfer for consumer applications. In Proceedings of the 13th European Conference on Power Electronics and Applications (EPE '09), Barcelona, Spain, 8-10 September 2009; pp. 1-10.

15. Liu, X.; Hui, S. Simulation Study and Experimental Verification of a Universal Contactless Battery Charging Platform With Localized Charging Features. IEEE Trans. Power Electron. 2007, 22, 2202-2210. [CrossRef]

16. Chen, Q.; Wong, S.C.; Tse, C.K.; Ruan, X. Analysis, Design, and Control of a Transcutaneous Power Regulator for Artificial Hearts. IEEE Trans. Biomed. Circuits Syst. 2009, 3, 23-31. [CrossRef] [PubMed]

17. Sato, F.; Nomoto, T.; Kano, G.; Matsuki, H.; Sato, T. A New Contactless Power-Signal Transmission Device for Implanted Functional Electrical Stimulation (FES). IEEE Trans. Magn. 2004, 40, 2964-2966. [CrossRef]

18. Villa, J.; Llombart, A.; Sanz, J.; Sallan, J. Practical Development of a 5 kW ICPT System SS Compensated with a Large Air gap. In Proceedings of the 2007 IEEE International Symposium on Industrial Electronics, Vigo, Spain, 4-7 June 2007. [CrossRef]

19. Kim, J.; Kim, J.; Kong, S.; Kim, H.; Suh, I.-S.; Suh, N.P.; Cho, D.; Kim, J.; Ahn, S. Coil Design and Shielding Methods for a Magnetic Resonant Wireless Power Transfer System. Proc. IEEE 2013, 101, 1332-1342. [CrossRef]

20. Zhu, Q.; Wang, L.; Guo, Y.; Liao, C.; Li, F. Applying LCC Compensation Network to Dynamic Wireless EV Charging System. IEEE Trans. Ind. Electron. 2016, 63, 6557-6567. [CrossRef]

21. Zaheer, A.; Neath, M.; Beh, H.Z.Z.; Covic, G.A. A Dynamic EV Charging System for Slow Moving Traffic Applications. IEEE Trans. Transp. Electrif. 2017, 3, 354-369. [CrossRef]

22. Song, K.; Zhu, C.; Koh, K.-E.; Kobayashi, D.; Imura, T.; Hori, Y. Modeling and design of dynamic wireless power transfer system for EV applications. In Proceedings of the IECON 2015-41st Annual Conference of the IEEE Industrial Electronics Society, Yokohama, Japan, 9-12 November 2015. [CrossRef]

23. Tavakoli, R.; Pantic, Z. Analysis, Design and Demonstration of a 25-kW Dynamic Wireless Charging System for Roadway Electric Vehicles. IEEE J. Emerg. Sel. Top. Power Electron. 2017, 1. [CrossRef]

24. Maglaras, L.A.; Topalis, F.V.; Maglaras, A.L. Cooperative approaches for dymanic wireless charging of Electric Vehicles in a smart city. In Proceedings of the 2014 IEEE International Energy Conference (ENERGYCON), Cavtat, Croatia, 13-16 May 2014. [CrossRef]

25. Lukic, S.; Pantic, Z. Cutting the Cord: Static and Dynamic Inductive Wireless Charging of Electric Vehicles. IEEE Electr. Mag. 2013, 1, 57-64. [CrossRef]

26. Wang, Y.; Hu, X.; Yao, Y.; Liu, X.; Xu, D.; Cai, L.; Hu, B.; Hua, K. A dynamic wireless power transfer system with parallel transmitters. In Proceedings of the 2017 IEEE Transportation Electrification Conference and Expo, Asia-Pacific (ITEC Asia-Pacific), Harbin, China, 7-10 August 2017. [CrossRef]

27. Jayakumar, A.; Chalmers, A.; Lie, T.T. A Review of Prospects for Adoption of Fuel Cell Electric Vehicles in New Zealand. IET Electr. Syst. Transp. 2017, 7, 259-266. [CrossRef]

28. Lu, F.; Zhang, H.; Hofmann, H.; Mi, C.C. A Dynamic Charging System with Reduced Output Power Pulsation for Electric Vehicles. IEEE Trans. Ind. Electron. 2016, 63, 6580-6590. [CrossRef]

29. Jeong, S.; Jang, Y.J.; Kum, D. Economic analysis of the dynamic charging electric vehicle. IEEE Trans. Power Electron. 2015, 30, 6368-6377. [CrossRef]

30. Gilchrist, A.; Wu, H.; Sealy, K. Novel system for wireless in-motion EV charging and disabled vehicle removal. In Proceedings of the 2012 IEEE International Electric Vehicle Conference, Greenville, SC, USA, 4-8 March 2012; pp. 1-4. [CrossRef]

31. Chopra, S.; Bauer, P. On-road contactless power transfer-Case study for driving range extension of EV. In Proceedings of the IECON 2011-37th Annual Conference of the IEEE Industrial Electronics Society, Melbourne, VIC, Australia, 7-10 November 2011; pp. 329-338. [CrossRef]

32. Tesla, N. Art of Transmitting Electrical Energy through Natural Medium. U.S. Patent 1,119,732, 1905. 
33. Tesla, N. Apparatus for Transmitting Electrical Energy. U.S. Patent 1,119,732, 1914.

34. Bolger, J.G.; Kirsten, F.A. Investigation of the Feasibility of a Dual Mode Electric Transportation System; Tech. Rep. LBL6301; Lawrence Berkeley Nat. Lab.: Berkeley, CA, USA, 1977.

35. Bolger, J.G.; Green, M.I.; Ng, L.S.; Wallace, R.I. Test of the Performance and Characteristics of a Prototype Inductive Power Coupling for Electric Highway Systems; Tech. Rep. LBL7522; Lawrence Berkeley Nat. Lab.: Berkeley, CA, USA, 1978.

36. Boys, J.T.; Covic, G.A. The Inductive Power Transfer Story at the University of Auckland. IEEE Circuit Syst. Mag. 2015, 15, 6-27. [CrossRef]

37. Hao, H.; Covic, G.A.; Boys, J.T. A Parallel Topology for Inductive Power Transfer Power Supplies. IEEE Trans. Power Electron. 2014, 29, 1140-1151. [CrossRef]

38. Miller, J.M.; Onar, O.C.; White, C.; Campbell, S.; Coomer, C.; Seiber, L.; Sepe, R.; Steyerl, A. Demonstrating Dynamic Wireless Charging of an Electric Vehicle: The Benefit of Electrochemical Capacitor Smoothing. IEEE Power Electron. Mag. 2014, 1, 12-24. [CrossRef]

39. Raju, S.; Wu, R.; Chan, M.; Yue, C.P. Modeling of Mutual Coupling between Planar Inductors in Wireless Power Applications. IEEE Trans. Power Electron. 2014, 29, 481-490. [CrossRef]

40. Acero, J.; Carretero, C.; Lope, I.; Alonso, R.; Lucia, O.; Burdio, J.M. Analysis of the Mutual Inductance of Planar-Lumped Inductive Power Transfer Systems. IEEE Trans. Ind. Electron. 2013, 60, 410-420. [CrossRef]

41. Moghadam, M.; Zhang, R. Multiuser Wireless Power Transfer via Magnetic Resonant Coupling: Performance Analysis, Charging Control, and Power Region Characterization. IEEE Trans. Signal Inf. Process. Netw. 2016, 2, 72-83. [CrossRef]

42. Yang, G.; Moghadam, M.; Zhang, R. Magnetic beamforming for wireless power transfer. In Proceedings of the 2016 IEEE International Conference on Acoustics, Speech and Signal Processing (ICASSP), Shanghai, China, 20-25 March 2016; pp. 3936-3940. [CrossRef]

43. Nagendra, G.R.; Covic, G.A.; Boys, J.T. Determining the Physical Size of Inductive Couplers for IPT EV Systems. IEEE J. Emerg. Sel. Top. Power Electron. 2014, 2, 571-583. [CrossRef]

44. Rakhymbay, A.; Bagheri, M.; Lu, M. A Simulation Study on Four Different Compensation Topologies in EV Wireless Charging. In Proceedings of the IEEE International Conference on Sustainable Energy Engineering and Application (ICSEEA), Jakarta, Indonesia, 23-24 October 2017.

45. Kan, T.; Nguyen, T.-D.; White, J.C.; Malhan, R.K.; Mi, C.C. A New Integration Method for an Electric Vehicle Wireless Charging System Using LCC Compensation Topology: Analysis and Design. IEEE Trans. Power Electron. 2017, 32, 1638-1650. [CrossRef]

46. Lu, F.; Zhang, H.; Hofmann, H.; Mi, C.C. An Inductive and Capacitive Integrated Coupler and Its LCL Compensation Circuit Design for Wireless Power Transfer. IEEE Trans. Ind. Appl. 2017, 53, 4903-4913. [CrossRef]

47. Liu, C.; Ge, S.; Li, H.; Guo, Y.; Cai, G. Double-LCL resonant compensation network for electric vehicles wireless power transfer: Experimental study and analysis. IET Power Electron. 2016, 9, 2262-2270. [CrossRef]

48. Zhu, G.; Gao, D.; Wang, S.; Chen, S. Misalignment tolerance improvement in wireless power transfer using LCC compensation topology. In Proceedings of the 2017 IEEE PELS Workshop on Emerging Technologies: Wireless Power Transfer (WoW), Chongqing, China, 20-22 May 2017; pp. 1-7. [CrossRef]

49. Greenhouse, H. Design of Planar Rectangular Microelectronic Inductors. IEEE Trans. Parts Hybrids Packag. 1974, 10, 101-109. [CrossRef]

50. Yu, D.; Han, K. Self-inductance of air-core circular coils with rectangular cross section. IEEE Trans. Mag. 1987, 23, 3916-3921. [CrossRef]

51. Luo, Y.; Chen, B. Improvement of Self-Inductance Calculations for Circular Coils of Rectangular Cross Section. IEEE Trans. Mag. 2013, 49, 1249-1255. [CrossRef]

52. Chen, W.; Liu, C.; Lee, C.; Shan, Z. Cost-Effectiveness Comparison of Coupler Designs of Wireless Power Transfer for Electric Vehicle Dynamic Charging. Energies 2016, 9, 906. [CrossRef]

53. Ongayo, D.; Hanif, M. Comparison of circular and rectangular coil transformer parameters for wireless Power Transfer based on Finite Element Analysis. In Proceedings of the 2015 IEEE 13th Brazilian Power Electronics Conference and 1st Southern Power Electronics Conference (COBEP/SPEC), Fortaleza, Brazil, 29 November-2 December 2015; pp. 1-6. [CrossRef]

54. Luo, Z.; Wei, X. Analysis of Square and Circular Planar Spiral Coils in Wireless Power Transfer System for Electric Vehicles. IEEE Trans. Ind. Electron. 2018, 65, 331-341. [CrossRef] 
55. Babic, S.; Akyel, C. New Analytic-Numerical Solutions for the Mutual Inductance of Two Coaxial Circular Coils with Rectangular Cross Section in Air. IEEE Trans. Mag. 2006, 42, 1661-1669. [CrossRef]

56. Grover, F.W. Inductance Calculation: Working Formulas and Tables; Dover: New York, NY, USA, 1946.

57. Babic, S.; Sirois, F.; Akyel, C.; Girardi, C. Mutual Inductance Calculation Between Circular Filaments Arbitrarily Positioned in Space: Alternative to Grovers Formula. IEEE Trans. Mag. 2010, 46, 3591-3600. [CrossRef]

58. Conway, J.T. Inductance Calculations for Noncoaxial Coils Using Bessel Functions. IEEE Trans. Mag. 2007, 43, 1023-1034. [CrossRef]

59. Babic, S.; Sirois, F.; Akyel, C.; Lemarquand, G.; Lemarquand, V.; Ravaud, R. New Formulas for Mutual Inductance and Axial Magnetic Force Between a Thin Wall Solenoid and a Thick Circular Coil of Rectangular Cross-Section. IEEE Trans. Mag. 2011, 47, 2034-2044. [CrossRef]

60. Ravaud, R.; Lemarquand, G.; Babic, S.; Lemarquand, V.; Akyel, C. Cylindrical Magnets and Coils: Fields, Forces, and Inductances. IEEE Trans. Mag. 2010, 46, 3585-3590. [CrossRef]

61. Kavitha, M.; Bobba, P.B.; Prasad, D. Effect of coil geometry and shielding on wireless power transfer system. In Proceedings of the 2016 IEEE 7th Power India International Conference (PIICON), Bikaner, India, 25-27 November 2016; pp. 1-6. [CrossRef]

62. Guo, Y.; Wang, L.; Liao, C.; Zhang, J.; Zhang, Y.; Zhang, Y. Conducted EMI Analysis for Switch-On Transient of Dynamic Wireless EV Charging System. In Proceedings of the 2016 IEEE Vehicle Power and Propulsion Conference (VPPC), Hangzhou, China, 17-20 October 2016; pp. 1-4. [CrossRef]

(C) 2018 by the authors. Licensee MDPI, Basel, Switzerland. This article is an open access article distributed under the terms and conditions of the Creative Commons Attribution (CC BY) license (http:/ / creativecommons.org/licenses/by/4.0/). 